\title{
BAILLARGER AND JACKSON: THE PRINCIPLE OF BAILLARGER-JACKSON IN APHASIA*
}

\author{
BY \\ Th. ALAJOUANINE
}

Paris

For a French neurologist whose neurological training has been carried out at the school of the Salpêtrière, Paris, Queen Square seems to be, in a certain way, London's Salpêtrière. This assumption may be partly true, since these two famous hospitals have been for years dedicated to the nursing and to the study of the diseases of the nervous system, and both have a rich and peculiar tradition and are proud to have inscribed great names in the golden book of neurological knowledge: on one side may be quoted the names of Hughlings Jackson, William Gowers, Victor Horsley, Kinnier Wilson, and on the other side the names of Charcot, Paul Broca, Déjèrine, Pierre Marie. But it would also be easy to prove the comparison to be partly erroneous as many differences may be noticed in the organization and the orientation of the two great centres, which are not only demonstrated by the fact that Queen Square is now an institute of neurology, whereas the Salpêtrière has not yet the same advantage.

Meanwhile, there always have been and there are still many spiritual exchanges between British and French neurology, though they appear less important, of course, than those which exist between Queen Square and the schools of English-speaking countries. It is concerning one of the first connexions between Queen Square and the Salpêtrière that I would attempt today a short evocation in this personal commemoration of the centenary of Queen Square. I shall speak of a remark made in 1865 by Baillarger and of the way Hughlings Jackson recognized its importance, giving to this subject an extraordinary development. These two connected works have brought, in my opinion, one of the most valuable interpretations of the physiopathology of aphasia. As this connexion appeared in 1865, this reminder would also be a sort of centenary recollection.

Baillarger, a physician at the Salpêtrière, already

\footnotetext{
* This paper was delivered on June 21, 1960, during the celebration to mark the centenary of the National Hospital, Queen Square. London.
}

well known by his work on the histology of the cerebral cortex and on hallucinations, took part in a long discussion that occurred in 1865 at the Medical Academy of France on the occasion of a report read by Lelut about the work of Dax who, 30 years before Broca, had ventured to locate speech in the left hemisphere of the brain; many opinions were ventilated during the long meetings necessary to get through this discussion, which lasted for many weeks. In a short, but substantial intervention, Baillarger drew attention to the manner aphasic patients may in certain conditions pronounce words they are unable to utter in ordinary circumstances. This important remark did not seem to have given rise to any valuable commentary. However, this was not the case on the other side of the Channel as we shall see in the writings of Jackson.

Here is the quotation (which I translate from the French) of the most significant lines of Baillarger's paper:

"During the observation of aphasic patients, you may notice this singular phenomenon, that it is impossible for them to pronounce certain words when they try to do so, even when they put in action all their will power, on the contrary, a moment after, they are able to pronounce the same words in an involuntary fashion; so, there is in these patients loss of voluntary motor action and a persistence of spontaneous motor action."

These remarks did not escape the acute attention of Hughlings Jackson who did not fail to attribute to Baillarger the importance of such an observation: Jackson, indeed, always with courtesy and loyalty rendered unto Caesar that which was due to Caesar; he never neglected to ascribe any minor fact he utilized to its proper author, even when a single blade of corn gathered by him had given birth in his hands to a rich harvest, so, a year after, in 1866, a paper was published in the Medical Times and Gazette, under the title "Notes on the Physiology and Pathology of Language: Remarks on those Cases of Disease of the Nervous System in which Defect of Expression is the Most Striking Symptom", he wrote: 
"M. Baillarger has already, I find, considered this question in an admirable manner. He says (the quotation is in French so I leave it in French): 'L'analyse des phénomènes conduit à reconnaître, dans certains cas de ce genre, que l'incitation verbale involontaire persiste, mais que l'incitation verbale volontaire est abolie. Quant à la perversion de la faculté du langage caractérisée par la prononciation de mots incohérents, la lesion consiste encore dans la substitution de la parole automatique à l'incitation verbale volontaire'. In the following sentence $a$ propos of a particular case, he spoke in more general terms: 'Il est bien évident qu'ici l'incitation motrice volontaire était abolie et que l'incitation motrice spontanée persistait'."

But it is especially in the second of the three famous papers published in Brain in 1879-1880, under the title "On affections of speech from disease of the brain", that Hughlings Jackson specifically recognized what he called Baillarger's principle, and gave a full and exhaustive demonstration of its importance. The footnote at the beginning of this paper may be quoted, as it shows how true is what I said before about his scrupulous quotations:

"I should like to remark that one very general conclusion to which the several facts so far stated and facts afterwards to be stated, point, was in principle long ago formulated by M. Baillarger. So far back as 1866, in the Medical Times and Gazette, I made the following quotations from his writings, which I now reproduce [here is the same quotation as before, at that time in French ] . . . I ought to have reproduced his quotation in the first instalment of this article, as evidently I am following pretty closely the principle this distinguished Frenchman has laid down. I fear M. Baillarger's acute remarks have attracted little attention, and I say with regret that I had forgotten them. I do not remember from what book I took the quotation."

If the remarks of Baillarger have not been lost in the long and immoderate discussions of the French Medical Academy we owe this to Hughlings Jackson. But it would not be enough to thank him for this resurrection; the way he has developed what he has called "Baillarger's principle", giving an admirable series of examples for his illustration and extension, and the manner it has been integrated within the Jacksonian thought, are of such importance that one must not continue to speak with him of Baillarger's principle but of the principle of Baillarger-Jackson, as proposed a long time ago, in different papers, with Ombredane and Mozziconacci.

It is not possible to give more than a short abstract of the facts and ideas Hughlings Jackson has brought to light in this field of expression in aphasia. Everyone knows what an admirable study he made on the utterances of aphasic patients, which he divided into two classes, recurring and occasional; to recall some of these observations will be the best way to emphasize the significance of what we call the Baillarger-Jackson principle.

An utterance, Jackson has said, "is or is not a proposition according as it is used". This is one of the keys he offers to analyse the utterances of aphasic patients and the first demonstration he gave is the way these patients are able to use the simple words "yes" or "no". He describes different cases:

"(1) The patient may utter yes or no, or both, in different tones, merely according as he is thus or thus excited; it is therefore not a proposition, but an interjection, a mere vehicle for variations of voice, expressing a feeling. (2) He may have this service of the words and be able also to reply with them: the latter is a propositional use of them".

In such cases Jackson observed that there is evidence that emotional language is not affected, but, as "to speak is to propositionize", according to the famous Jacksonian sentence, in the first group we have only verbal utterances devoid of propositional function, and so is established the law of dissociation between emotional and propositional uses of speech.

In the second class, occasional utterances, Hughlings Jackson found three different conditions: (1) Utterances which are not speech (oaths, interjections) which are also parts of emotional language, ranging from "oh!", "ah!", "Dear me", to "God bless my life"; (2) utterances which are speech, buto inferior speech: "they are of the same order", wrote $\overrightarrow{0}$ Jackson, "in so far as they show conservation o\$ automatic with loss of voluntary action": the examples given here are well known: "merci" 迎 Trousseau's case, "good-bye", "take care". . . ه These words are produced under conditions of situation or circumstance; it is an inferior speech $\rightarrow$ "old speech" or "ready made speech", as Jackso" called them; their occasional appearance, the im- . possibility for the patient to reproduce them when asked to repeat them, are also proofs of the lack of voluntary action; (3) utterances which are real speech with intellectual value.

The analysis of these different conditions, essentially based on an acute observation of facts, is fundamental to the Jacksonian interpretation of the physiopathology of speech disorders. Loss of voluntary incitation and conservation of the spontaneous one was the deduction of Baillarger; Jackson went farther and deeper: dissociation in the uses of speech, and more precisely, dissociation between emotional and intellectual language, between inferior and real speech, so fully completes the principle proposed by Baillarger, giving at the same time a demonstration of the impossibility of interpreting the lack of words of aphasic patients by an amnesic explanation.

In several papers, particularly in a paper pub- 을 lished five years ago in Brain (it was a Jackson 응 Memorial Lecture), I have shown how striking is the evolution of aphasia in cases of progressive im- 
provement as it offers another demonstration of the Baillarger-Jackson principle. During the regression of permanent verbal stereotypy one may note the increasing influence of the will. After the first stage where all voluntary speech is abolished and only a fixed and automatic verbal expression exists; later, as speech becomes more differentiated, the automatic utterance is checked by voluntary speech as the latter reappears. In agrammatism, which is often the end of such evolution, the same evolutive dissociation is found: voluntary speech shows agrammatism but ready-made or emotional automatic speech escapes such syntactic disorder. One could also demonstrate in the regression of jargon aphasia the substitution of voluntary influence for the loquacious, uncontrolled expression of these patients. A confirmation of Baillarger-Jackson's principle may also be found in the condition which may facilitate the uttering of deficient vocabulary: emotion is one of the most frequent of these features. The best example I had the occasion to observe was the case of an aphasic lady I examined in the presence of her daughter. When I asked this patient to tell me the Christian name of her daughter, she could not find it, and terribly upset, suddenly in a burst of emotion she said: "My poor Jacqueline, now I don't know your name any longer!" The name she could not utter voluntarily appeared easily in circumstances of intense excitement.
We do not know what is will in neurophysiological terms; we know how imprecise is what we call automatism. Meanwhile the dissociation between voluntary action and spontaneous action is a striking feature in diseases of the central nervous system, and especially in aphasia. Of course, we do not believe that it affords a complete explanation of aphasia, if there ever is one. But, it is surely one of the most important facts for the understanding of disorders of language, as Baillarger showed a century ago and as the genius of Hughlings Jackson has perfectly and fully amplified.

This short incursion into the history of aphasia in the company of the French physician of the Salpêtrière and the great physician of Queen Square, if it has the value of recording an historical AngloFrench event, intends, in my mind, to offer a tribute of gratitude and admiration to one of the greatest men of Queen Square. At the same time I wish it to affirm the permanence of friendship between French and British neurological schools. May I, to end, recall that I have had the honour and the pleasure of giving several lectures at Queen Square, and say that I owed this favour to the kindness of Sir Francis Walshe and Dr. Macdonald Critchley. But, so narrow have been my relations with Queen Square, I must confess it has not been enough to improve my continental accent, for which, having no anosognosia, I am sorry and wish to apologize. 